\title{
Global, regional, and national consumption levels of dietary fats and oils in 1990 and 2010: a systematic analysis including 266 country-specific nutrition surveys
}

The data supplement for this Research paper that is labelled "eTables 1-7" contains some errors (BMJ 2014;348:g2272, doi:10.1136/bmj.g2272). This supplement shows details of world regions and countries used in the study, characteristics of data sources, and consumption levels of dietary fats and oils analysed. However, some of the rows in eTables 3, 4, 5, 6, and 7 became mixed up when the file was converted from Excel to
Word. Please see the linked data supplement in this correction for the correct versions of eTables 3-7 http://www.bmj.com/ content/350/bmj.h1702/related.

Cite this as: BMJ 2015;350:h1702

๑ BMJ Publishing Group Ltd 2015 